\title{
Publisher Correction: 2021 in review
}

Correction to: Nature Microbiology https://doi.org/10.1038/s41564-021-01016-5, published online 24 November 2021.

In the version of this article initially published online, there was an error. At the end of the tenth paragraph, in the sentence now reading "Another study in the plant-pathogenic oomycete Phytophthora showed that it slices through the plant surface during host invasion using a mechanism that resembles the cutting of a sharp Japanese knife ${ }^{31}$ ", the word "fungus" mistakenly appeared in place of "oomycete".

The correction has been made to the online version of the article.

Published online: 30 November 2021

https://doi.org/10.1038/s41564-021-01038-Z

๑ Springer Nature Limited 2021 